\title{
Polymer Electrolyte Membranes for High Temperature PEMFC
}

\section{Lee-Jin Ghil and Hee-Woo Rhee*}

Department of Chemical and Biomolecular Engineering, Sogang University, Seoul, Republic of Korea

(hwrhee@sogang.ac.kr)

PEMFC has been in great interest because it offers high power density and efficiency for various applications such as electric vehicles, portable electronics and residential power generation. Sulfonic acid-based membranes, represented by Nafion $^{\circledR}$, have to be hydrated for the electrolytes to be very conductive and this restriction limits the operation temperature of PEMFC less than $80{ }^{\circ} \mathrm{C}$.

When PEMFC is operated at high temperatures above $100{ }^{\circ} \mathrm{C}$, it assures much faster reaction rate along with additional advantages such as prevention of catalyst poisoning by $\mathrm{CO}$, higher system efficiency and better water management.

Thus, we developed two types of membranes which had phosphonic acid groups which do not require the hydration due to their self-dissociation nature. The first one was Nafion nanocomposite using phosphonic acid functionalized ZrP (zirconium diphosphophenyl phosphate, Zr3P). The nanocomposite membrane showed higher proton conductivity $\left(\sim 0.025 \mathrm{~S} / \mathrm{cm}\right.$ at $\left.120{ }^{\circ} \mathrm{C},<30 \% \mathrm{RH}\right)$ and resulted in good cell performance at high temperature $\left(250 \mathrm{~mA} / \mathrm{cm}^{2}\right.$ at $0.6 \mathrm{~V}$ at $\left.120{ }^{\circ} \mathrm{C}\right)$.

Also, we synthesized the thermostable material that had phosphonic acid groups based on poly(dimethyl siloxane) (PDMS). We introduced 3-aminopropyl triethoxysilane (APTES) and tetraethyl orthosilicate (TEOS) to form nanopores and treated them with phosphorous oxychloride $\left(\mathrm{POCl}_{3}\right)$. And PDMS connected the nanopores by sol-gel method. Thus, intrinsically PDMS was modified to be amphiphilic by substituting end groups with phosphonic acid groups, which result in the phase separation between hydrophobic PDMS and hydrophilic phosphonic acid groups. The phase separation would form the proton conducting channels in the membrane which would assure high proton conductivity $\left(0.06 \mathrm{~S} / \mathrm{cm}\right.$ at $\left.20 \sim 130{ }^{\circ} \mathrm{C}\right)$.

Due to such high proton conductivities and conducting mechanism of phosphonic acid groups, they could be used for high temperature PEMFC at low humid conditions

\section{References}

1. R. Savinell, E. Yeager, D. Tryk, U. Landau, J. Wainright, D. Weng, K. Lux, M. Litt, C. Rogers: J. Electrochem. Soc. 141 (1994) 46. 